\title{
Large cell neuroendocrine carcinoma of the lung: A clinicopathologic study of eighty-seven cases
}

\author{
Hidefumi Takei, MD ${ }^{a, b}$ \\ Hisao Asamura, MD ${ }^{\text {b }}$ \\ Arafumi Maeshima, MD ${ }^{\mathrm{c}}$ \\ Kenji Suzuki, MD ${ }^{\mathrm{b}}$ \\ Haruhiko Kondo, $M D^{\mathrm{b}}$ \\ Toshiro Niki, MD \\ Tesshi Yamada, MD ${ }^{\mathrm{c}}$ \\ Ryosuke Tsuchiya, $\mathrm{MD}^{\mathrm{a}, \mathrm{b}}$ \\ Yoshihiro Matsuno, $\mathrm{MD}^{\mathrm{a}}$
}

From the Clinical Laboratory Division ${ }^{\mathrm{a}}$ and Thoracic Surgery Division, ${ }^{\mathrm{b}}$ National Cancer Center Hospital, and Pathology Division, National Cancer Center Research Institute, ${ }^{\mathrm{c}}$ Tokyo, Japan.

Supported in part by Grants-in-Aid for Cancer Research (11-19 and 12-5) from the Ministry of Health, Labor, and Welfare of Japan.

Received for publication Sept 5, 2001; revisions requested Oct 19, 2001; revisions received Nov 26, 2001; accepted for publication Dec 20, 2001.

Address for reprints: Yoshihiro Matsuno, MD, Clinical Laboratory Division, National Cancer Center Hospital, 1-1, Tsukiji 5 chome, Chuo-ku, Tokyo, 104-0045, Japan (E-mail: ymatsuno@ncc.go.jp).

J Thorac Cardiovasc Surg 2002;124:285-92

Copyright () 2002 by The American Association for Thoracic Surgery

$0022-5223 / 2002 \$ 35.00+0 \quad \mathbf{1 2 / 1 / 1 2 2 5 2 3}$

doi: $10.1067 / \mathrm{mtc} .2002 .122523$
Objective: Large cell neuroendocrine carcinoma of the lung is a newly recognized clinicopathologic entity. The clinical characteristics and optimal treatment of patients with large cell carcinomas are not yet established. The aim of this study was to define the clinicopathologic characteristics of large cell neuroendocrine carcinoma.

Methods: The histologic characteristics of the patients receiving an initial diagnosis of poorly differentiated non-small cell lung carcinoma $(n=484)$, small cell carcinoma $(n=55)$, carcinoid $(n=31)$, and large cell neuroendocrine carcinoma $(\mathrm{n}=12)$ were retrospectively reviewed according to World Health Organization criteria. Immunohistochemistry was performed to confirm the neuroendocrine phenotype. The outcomes and other clinical characteristics of those patients with large cell neuroendocrine carcinoma were retrospectively analyzed and compared with those of patients with poorly differentiated carcinoma of other histologic types.

Results: A total of 87 patients were given a diagnosis of large cell neuroendocrine carcinoma after the histologic review. These patients comprised $3.1 \%$ of all patients undergoing resection for primary lung cancer during the same period. The overall 5 -year survival was $57 \%$. The 5-year survivals of patients with stage I, II, III, and IV disease were $67 \%, 75 \%, 45 \%$, and $0 \%$, respectively. There was no statistically significant difference between the overall survival of patients with large cell neuroendocrine carcinoma and those with other non-small cell lung cancers. There was a significant difference between the survival of patients with stage I large cell neuroendocrine carcinoma and that of patients with the same stage of other nonsmall cell lung carcinomas. The site of the first documented recurrence was locoregional in 12 patients (34\%), distant metastases in 20 patients $(57 \%)$, and both simultaneously in 3 patients. Locoregional lymph node recurrences were observed frequently. More than $80 \%$ of recurrences were found within 1 year after the operation.

Conclusion: In terms of prognosis, large cell neuroendocrine carcinoma is distinctly different from other non-small cell lung cancers. The prognosis of large cell neuroendocrine carcinoma was poor, even for early stage disease; the prognosis of the stage I disease of large cell neuroendocrine carcinoma was poorer than that of the same stage of other non-small cell lung cancers. Because of its aggressive clinical behavior and poor prognosis, large cell neuroendocrine carcinoma should be recognized as one of the poorest prognostic subgroups among primary lung cancers, and therefore novel therapeutic approaches should be established. 


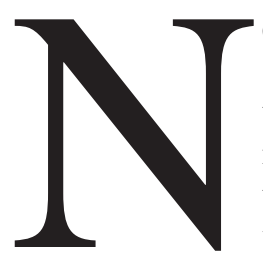

euroendocrine tumors of the lung represent a wide spectrum of pathologic entities. On the basis of histologic characteristics and clinical behavior, at one end of the spectrum are typical carcinoid tumors, with a low incidence of metastases and excellent prognosis after surgical resection. At the other end of the spectrum are small cell carcinomas (SCLCs) that metastasize early. Between these extremes, there is atypical carcinoid, as proposed by Arrigoni and colleagues ${ }^{1}$ in 1972. Travis and coworkers ${ }^{2}$ attempted to define tumors with wide histologic similarity with oat cell carcinoma consisting of large cells and proposed large cell neuroendocrine carcinoma (LCNEC) as the fourth category among neuroendocrine tumors of the lung. ${ }^{3-7}$ The histologic criteria of LCNEC proposed by the World Health Organization (WHO) in 1999 were as follows ${ }^{8}$ : (1) a tumor with a neuroendocrine morphologic features (organoid nesting, palisading, rosettes, and trabeculae); (2) high mitotic rate of 11 or greater per $2 \mathrm{~mm}^{2}$; (3) necrosis (often large zones); and (4) cytologic features of a non-small cell carcinoma (NSCLC; ie, large cell size, low nuclear/cytoplasmic ratio, vesicular or fine chromatin, and/or frequent nucleoli). Although a few studies have described the clinicopathologic features of LCNEC, ${ }^{9-11}$ these studies contain a rather small number of cases. The present study is based on the largest series of LCNEC cases from a single institute. The aim of this study was to delineate the clinical characteristics and prognosis of patients with LCNEC.

\section{Methods \\ Patients}

Of 2790 patients who underwent surgical resection for primary lung cancer during the 18-year period between 1982 and 1999 at the National Cancer Center Hospital, Tokyo, 572 patients with the following histologic diagnoses were reviewed to extract cases of LCNEC: poorly differentiated adenocarcinoma $(\mathrm{n}=216)$; poorly differentiated squamous cell carcinoma $(\mathrm{n}=141)$; large cell carcinoma (LCC, $\mathrm{n}=117)$; SCLC $(\mathrm{n}=55)$; carcinoid tumor $(\mathrm{n}=$ $31)$; and LCNEC $(\mathrm{n}=12)$. During this period, atypical carcinoid was not identified in our pathology files.

\section{Pathology Review}

According to the histologic criteria described in the WHO classification, ${ }^{8}$ representative routine hematoxylin and eosin-stained sections of these 572 patients were independently reviewed by 3 investigators (H.T., Y.M., and A.M.), and discrepancies were resolved by means of joint view of the slides under a multiheaded microscope. A representative photomicrograph of LCNEC is shown in Figure 1. Immunohistochemistry was performed to confirm the neuroendocrine phenotype. One of the representative formalin-fixed, paraffin-embedded tissue blocks of each case was selected for immunostaining. The sections were autoclaved for 10 minutes in $10 \mathrm{mmol} / \mathrm{L}$ citrate buffer $(\mathrm{pH}, 6.0)$ for antigen retrieval before incubation with the primary antibody. Primary antibodies against 3 neuroendocrine markers, neural cell adhesion molecule (NCC-Lu-243, Nippon Kayaku Co, Ltd, Tokyo, Japan), chromogranin A (DAKO Corporation, N.S., Glostrup, Denmark), and synaptophysin (DAKO), were used. Immunoreaction was detected by using a labeled streptavidin-biotin method and was visualized with 3,3'-diaminobenzidine, followed by counterstaining with hematoxylin. The degree of immunostaining of the neuroendocrine markers was scored as negative, focal $(<10 \%$ of tumor cells stained; Figure 2, A), patchy (10\%-50\% stained; Figure $2, B)$, and diffuse $(>50 \%$ stained; Figure $2, C)$. A tumor that stained focally for at least one of the 3 neuroendocrine markers was judged positive for neuroendocrine phenotype. A revised diagnosis of LCNEC was made when the neuroendocrine phenotype was confirmed and when all 3 investigators agreed with the diagnosis.

\section{Clinical Findings and Statistical Analysis}

Clinical information was extracted from medical records. The stage of disease was based on the TNM classification using the International Union Against Cancer (UICC) staging system. ${ }^{12}$ The overall survival of the patients was calculated by means of the Kaplan-Meier methods. ${ }^{13}$ Comparison of survival curves of different categories between patients with LCNEC and patients diagnosed as having disease of other histologic types was performed by log-rank tests.

\section{Results}

\section{Pathology Review}

Eighty-eight of 572 patients who underwent pathology review had histologic morphologic characteristics of LCNEC. Because 1 of the patients had negative results for all 3 neuroendocrine markers, the case was excluded from the LCNEC category and was categorized as LCC in further analysis. The remaining 87 patients had positive results for at least 1 of 3 neuroendocrine markers. Each of the 3 neuroendocrine markers was expressed in more than $80 \%$ of LCNEC cases (Table 1). Fifty-nine (68\%) of the patients had positive results for all 3 neuroendocrine markers (Table 2). Less than half of the cases stained diffusely in each immunohistochemical section. Eighty-seven patients with LCNEC comprised $3.1 \%$ of all the patients who underwent surgical resection for primary lung cancer during the same period. The results of histologic review are shown in Table 3. Twenty-four (44\%) of 55 patients with SCLCs were converted to LCNEC. Five patients with LCNEC were combined with other histologic types of NSCLC (squamous cell carcinoma in 2, adenocarcinoma in 1, both squamous cell carcinoma and adenocarcinoma in 1, and LCC in 1).

\section{Clinical Profiles}

Of the 87 patients with LCNEC identified, 77 were men and 10 were women. Mean age was 68 years (range, 37-82 years). Eighty-five (98\%) patients had a history of habitual cigarette smoking. The level of serum carcinoembryonic antigen was increased in 42 (49\%) of 86 patients. An elevation of the level of serum neuron-specific enolase and 

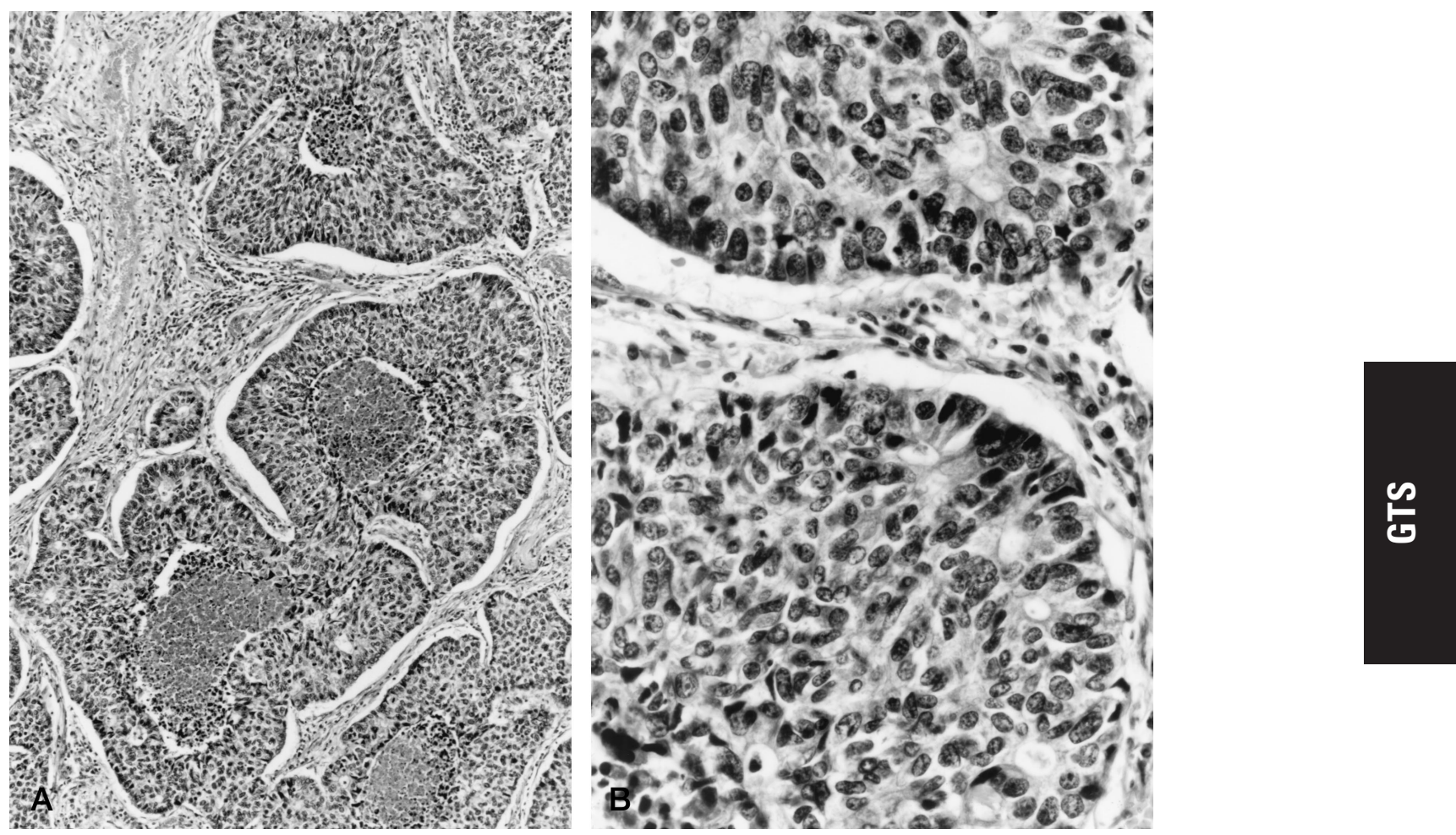

Figure 1. A, Representative photomicrograph of LCNEC. Organoid pattern, palisading, and necrosis are shown. (Hematoxylin and eosin; original magnification $100 \times$.) B, Tumor cells are large and polygonal with abundant and finely granular cytoplasm, easily discernible nucleoli in some cells. Note also rosette-like structures. (Hematoxylin and eosin; original magnification $400 \times$.)

pro-gastrin-releasing peptide was found in $8(19 \%)$ of 48 patients and in $1(11 \%)$ of 9 patients, respectively. No evidence of paraneoplastic syndrome was found in any of the 87 patients at the presentation. The postoperative stage distribution of 87 patients, according to the UICC staging system, was as follows: IA, 20; IB, 21; IIA, 3; IIB, 10; IIIA, 17; IIIB, 13; and IV, 3. The operative mode performed was as follows: pneumonectomy, 12 patients; bilobectomy, 6 patients; lobectomy, 61 patients; and limited resection, 8 patients. A complete mediastinal lymph node dissection was performed in $60(69 \%)$ patients, and mediastinal lymph node metastasis was found in 17 (28\%) of these patients.

Preoperative chemotherapy was administered for 5 patients, and a substantial response was observed in 1 patient. A total of 12 patients had postoperative chemotherapy. Because of the original histologic diagnosis of SCLC, 11 patients received postoperative chemotherapy with a cisplatin-based regimen. Tumor recurrences were observed in 5 $(46 \%)$ patients of this group.

\section{Prognosis}

Thirty-one patients died of LCNEC, and 4 patients were alive with LCNEC. The survival of patients with LCNEC, other poorly differentiated NSCLC $(n=426)$, LCC $(n=$
102), and SCLC $(\mathrm{n}=31)$ was compared for all stages (Figure 3). The overall 5-year survival of 87 patients with LCNEC was $57 \%$. The 5-year survivals of patients with stage I, II, III, and IV disease were $67 \%, 75 \%, 45 \%$, and $0 \%$, respectively. No significant difference was found in survival between patients with LCNEC and those with other poorly differentiated NSCLC $(P=.91)$, between patients with LCNEC and LCC $(P=.13)$, and between patients with LCNEC and SCLC $(P=.59)$. The survival was further analyzed for patients with stage I disease. The 5-year survivals of patients with stage I LCNEC, poorly differentiated NSCLC, and LCC were $67 \%, 88 \%$, and $92 \%$, respectively. There were significant difference in survival between the patients with LCNEC and those with poorly differentiated NSCLC $(P=.003$, Figure 4$)$ and between patients with LCNEC and those with LCC ( $P=.03$, Figure 5). However, there was no significant difference in survival between patients with stage I LCNEC and those with SCLC $(P=$ .87 , Figure 6 ). There was no correlation between the pattern of staining of neuroendocrine markers and survival.

Of the 87 patients with LCNEC, 35 patients experienced tumor recurrence. The sites of first-documented recurrence are shown in Table 4. Locoregional recurrence was ob- 


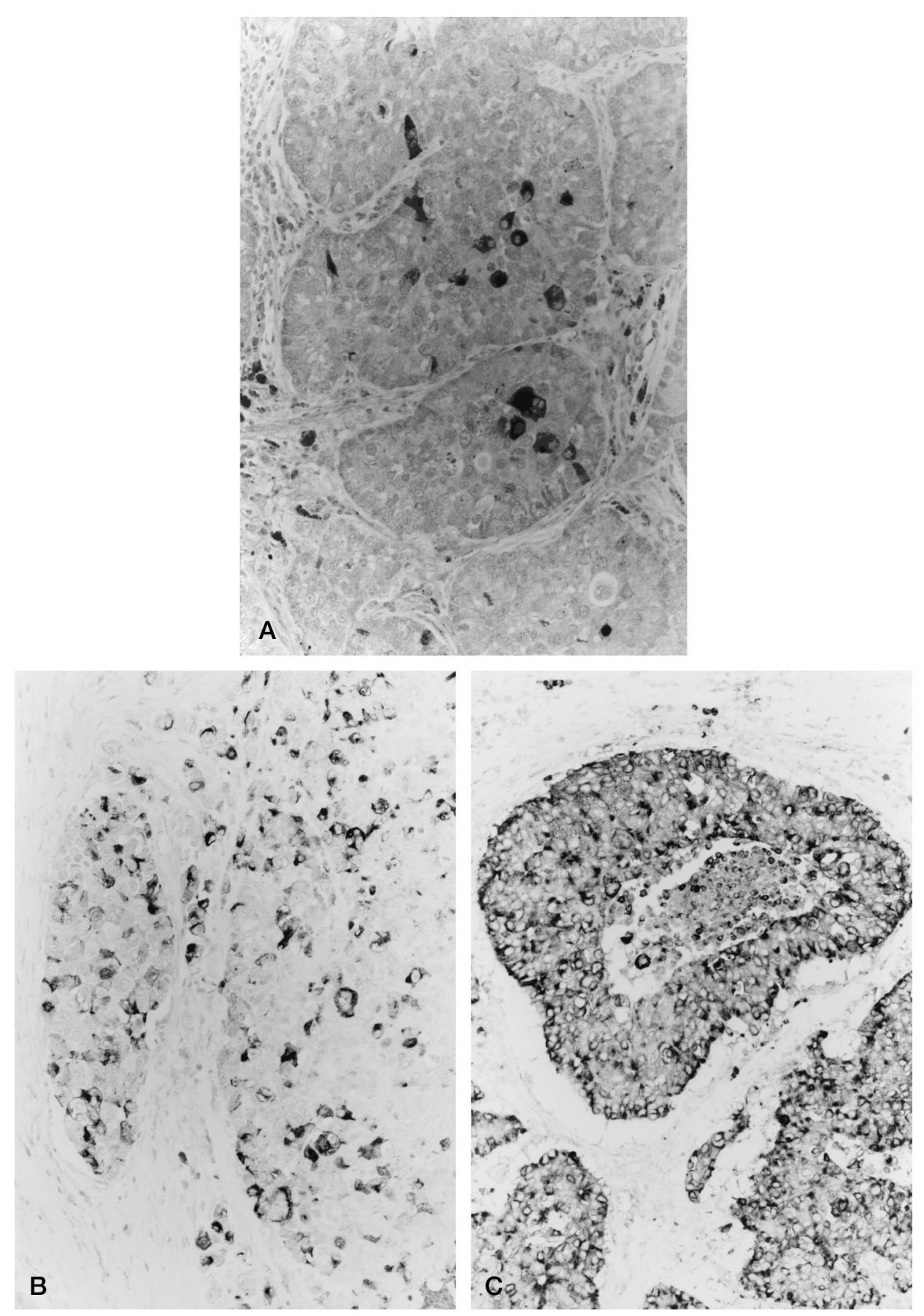

Figure 2. Representative staining of chromogranin A in LCNEC cases: A, Focal; B, patchy; C, diffuse. (Immunostain; original magnification $400 \times$.)

served in $44 \%$ of patients. The mediastinal and supraclavicular lymph nodes were a common site for locoregional recurrence. A majority of tumor recurrence was seen early after the operation: $82 \%$ within a year and $91 \%$ within 2 years (Table 5). Of 35 patients, 18 received radiotherapy for recurrence in a palliative setting. Complete response was radiologically observed in 5 patients.

\section{Discussion}

LCNEC of the lung was initially characterized by Travis and colleagues, ${ }^{2}$ forming a separate category of neuroendocrine tumors of the lung. Many different classification schemas of pulmonary neuroendocrine tumors have been proposed. ${ }^{3-9,14}$ In 1999 , the WHO proposed a new classification of pulmonary neuroendocrine tumors. ${ }^{8}$ The criteria for di- 
TABLE 1. Pattern of immunohistochemical staining for synaptophysin, neural cell adhesion molecule, and chromogranin A

\begin{tabular}{lccccc}
\hline & \multicolumn{4}{c}{ Pattern of immunohistochemical staining } \\
\cline { 2 - 6 } NE markers & Negative & Focal & Patchy & Diffuse & Positive/eligible case (\%) \\
\hline Synaptophysin & 8 & 25 & 14 & 38 & $77 / 85(91)$ \\
NCAM & 7 & 28 & 18 & 33 & $79 / 86(91)$ \\
Chromogranin A & 15 & 29 & 15 & 28 & $72 / 87(82)$ \\
\hline
\end{tabular}

$N E$, Neuroendocrine; NCAM, neural cell adhesion molecule.

TABLE 2. Neuroendocrine markers expressed per case

\begin{tabular}{lc}
\hline $\begin{array}{l}\text { No. of NE markers } \\
\text { expressed per case }\end{array}$ & No. of cases $(\%)$ \\
\hline At least 1 marker & $87(100)$ \\
At least 2 markers & $74(85)$ \\
All 3 markers & $59(68)$
\end{tabular}

$N E$, Neuroendocrine.

agnosis of LCNEC were authorized in this classification. However, the clinical behaviors of LCNEC remain unknown. The present study is the first to analyze a large number of patients with LCNEC according to the WHO classification. The patients with LCNEC in our series comprised $3.1 \%$ of all the patients undergoing surgical resection for primary lung cancer during the same period. The present findings agree with those of Jiang and associates, ${ }^{9}$ who reported that $2.8 \%$ of all the resected primary lung cancers were LCNECs in their series of patients. Thus, the actual incidence of LCNEC among resectable primary lung cancer appears to be around $3 \%$.

In the diagnosis of LCNEC, a discordance between histologic findings and immunohistochemical results may occasionally occur. Tumors showing neuroendocrine morphologic features but lacking the positive neuroendocrine phenotype can be called LCCs with neuroendocrine morphologic features. ${ }^{8}$ Whether such tumors behave as LCNEC or as LCC of nonneuroendocrine type remains controversial. In the present study there was only 1 patient with LCC with neuroendocrine morphologic features, probably because of the strict application of histologic criteria, the sensitive and reliable immunohistochemical technique for the 3 markers used, and the careful microscopic examination of its result. For chromogranin A staining, for example, a single but definitively positive tumor cell was counted as positive. This successful exclusion of LCC with neuroendocrine morphologic characteristics has made clinicopathologic analysis of LCNEC in this study understandable and reliable. However, the number of positive cells and their distribution was variable among patients, as shown in Table 1. Therefore, for the purpose of reliable preoperative pathologic diagnosis, it is worth exploring novel neuroendocrine
TABLE 3. Histologic review

\begin{tabular}{lcc}
\hline Initial diagnosis & $\begin{array}{c}\text { No. of } \\
\text { patients }\end{array}$ & $\begin{array}{c}\text { No. of patients given new } \\
\text { diagnosis of LCNEC (\%) }\end{array}$ \\
\hline P/D AD & 216 & $26(12)$ \\
P/D SO & 141 & $10(7)$ \\
LCC & 117 & $15(13)$ \\
SCLC & 55 & $24(44)$ \\
Carcinoid & 31 & 0 \\
LCNEC & 12 & 12 \\
Total & 572 & $87(15)$ \\
\hline
\end{tabular}

$P / D A D$, Poorly differentiated adenocarcinoma; $P / D S Q$, poorly differentiated squamous cell carcinoma.

markers that would label most of the tumor cells in the biopsy or cytology specimen.

Several unique clinical features of LCNEC were clearly demonstrated in the present study. ${ }^{2-9}$ Among them, male predominance of the affected patients and apparent association with habitual tobacco smoking may suggest the presence of common causative factors to squamous cell carcinoma, SCLC, and LCNEC. The prognosis of patients with LCNEC was significantly poorer than that of patients with other NSCLCs at stage I disease, which was almost comparable with that of patients with SCLC. Furthermore, the disease-free interval of the patients with LCNEC was much shorter. Thus, as demonstrated by a large number of cases in this study, LCNEC should be recognized as a high-grade malignancy. Obviously, it is important to separate LCNEC distinctly not only from typical and atypical carcinoid tumors but also from poorly differentiated NSCLC of other histologic types. As for tumor markers, previous studies showed that a serum level of pro-gastrin-releasing peptide was elevated at $70 \%$ for SCLC and at $2 \%$ to $4 \%$ for NSCLC. ${ }^{16-19}$ The elevation of serum neuron-specific enolase level was also reported in $40 \%$ to $60 \%$ of patients with SCLC and in 5\% to $20 \%$ of patients with NSCLC. $17,18,20,21$ Although the elevation of a serum level for these 2 makers was shown in the present study, it was not so frequent as was reported in SCLC. In terms of tumor markers, the pattern of elevation in serum level seemed to have some resemblance to those of NSCLC rather than those of SCLC.

Interobserver differences in the diagnosis of LCNEC 


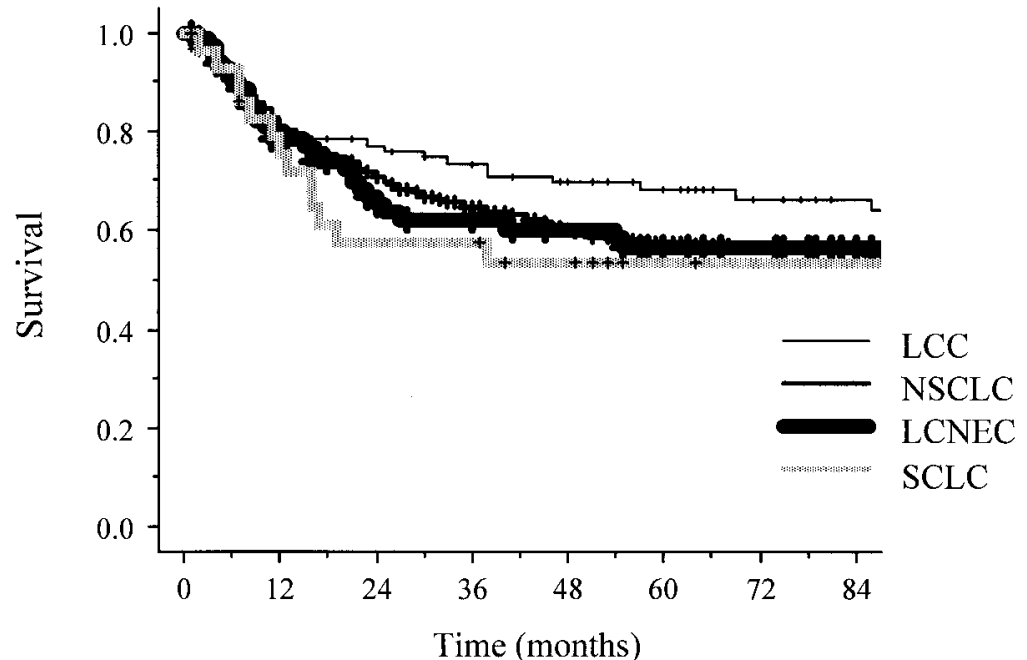

\begin{tabular}{|c|c|c|c|c|c|c|c|c|}
\hline \multicolumn{9}{|c|}{ No, of patients at risk } \\
\hline $\mathrm{LCC}$ & 102 & 71 & 64 & 58 & 52 & 47 & 37 & 32 \\
\hline NSCLC & 426 & 304 & 248 & 210 & 180 & 150 & 120 & 97 \\
\hline LCNEC & 87 & 56 & 42 & 38 & 35 & 26 & 23 & 14 \\
\hline SCLC & 31 & 22 & 17 & 16 & 13 & 9 & 8 & 8 \\
\hline
\end{tabular}

Figure 3. Survival curves of patients with LCNEC $(n=87)$, other poorly differentiated NSCLCs $(n=426)$, LCC $(n=$ 102), and SCLC $(n=31)$ for all stages.

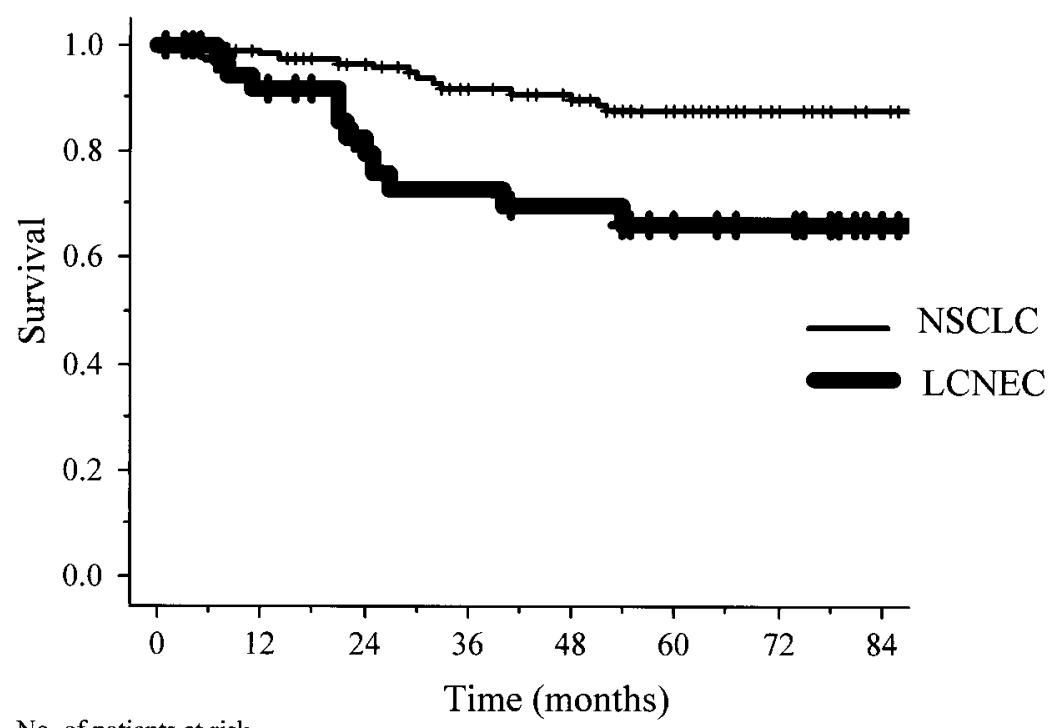

No. of patients at risk

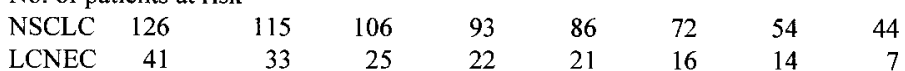

Figure 4. Survival curves of 41 patients with LCNEC of stage I and 126 patients with other poorly differentiated NSCLCs of stage I (P=.003, log-rank test).

should be investigated. ${ }^{23}$ In the course of establishment of the WHO histologic criteria, Travis and colleagues ${ }^{23}$ studied interobserver differences in the application of the proposed criteria. In their study the observers were the members of the WHO pathology committee who repeatedly examined and discussed cases together and then described the criteria. Even in that study they commented that separation between LCNEC and SCLC appeared to be problematic. In the present study, $44 \%$ (24 patients) of the previously diagnosed cases of SCLC were reclassified as LCNEC after the 


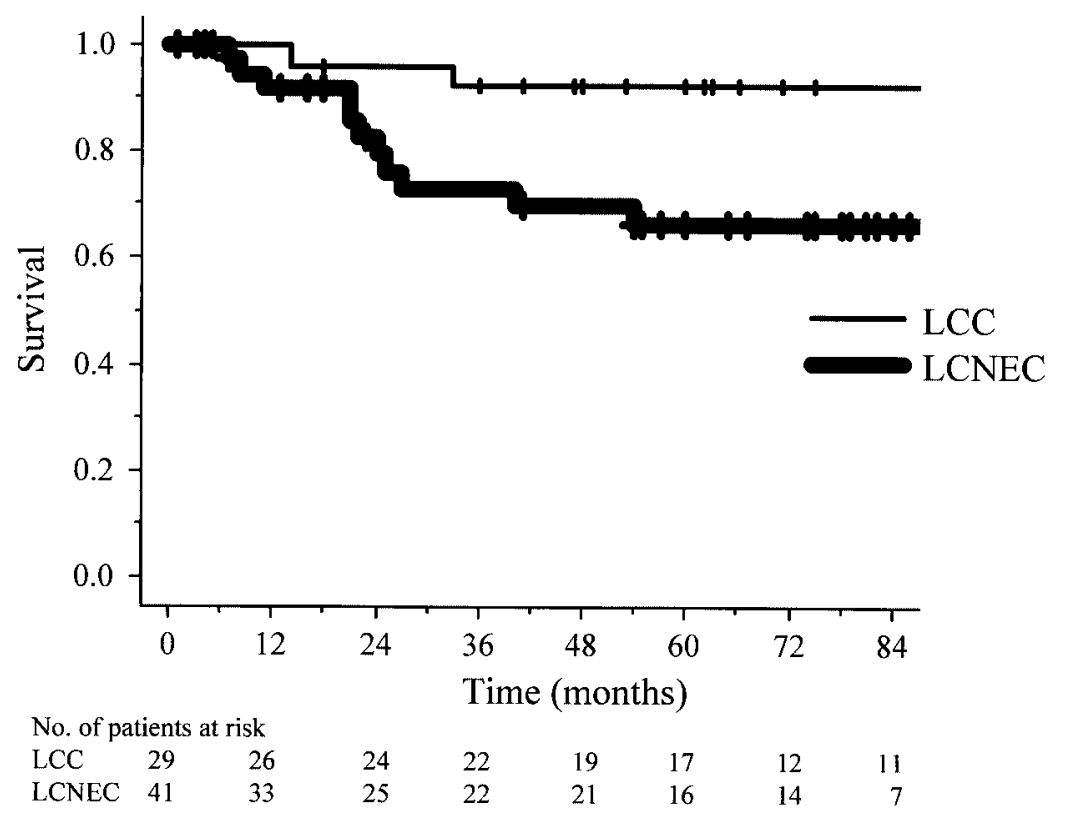

Figure 5. Survival curves of 41 patients with LCNEC of stage I and 29 patients of LCC of stage I $(P=.03$, log-rank test).

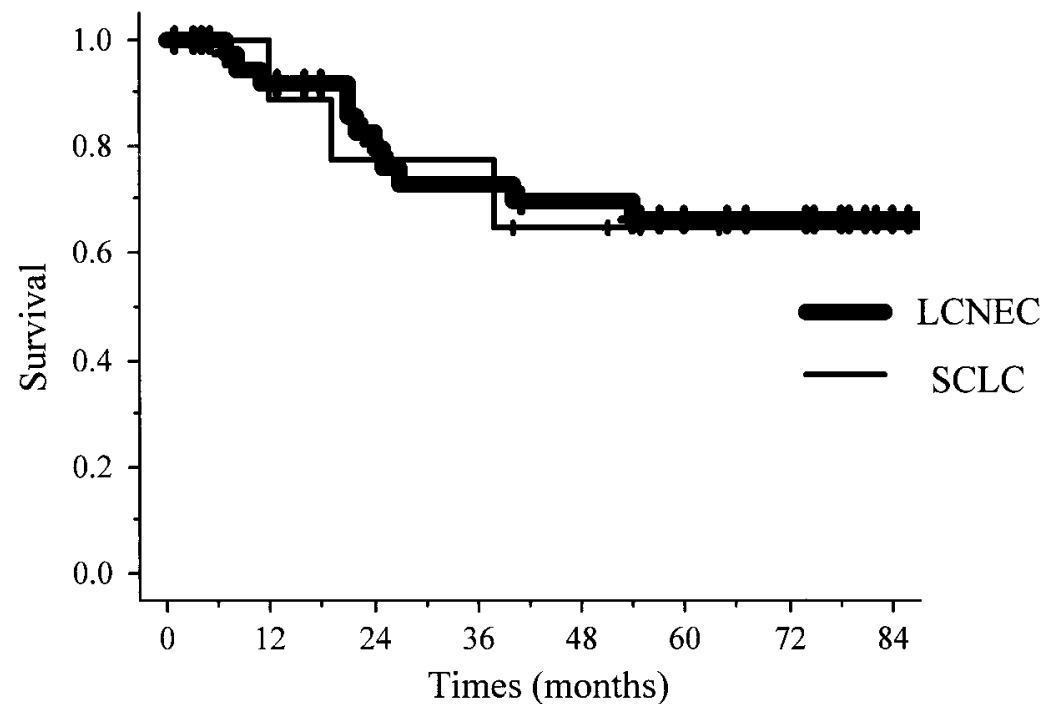

No. of patients at risk

$\begin{array}{lrrrrrrrr}\text { LCNEC } & 41 & 33 & 25 & 22 & 21 & 16 & 14 & 7 \\ \text { SCLC } & 9 & 8 & 7 & 7 & 4 & 2 & 1 & 1\end{array}$

Figure 6. Survival curves of 41 patients with LCNEC of stage I and 9 patients with SCLC of stage I $(P=.87$, log-rank test).

review that required agreement by 3 investigators. As for the 24 cases, most of which were initially diagnosed as SCLC of intermediate cell type, the changes of histologic diagnosis from SCLC to LCNEC were mainly based on the cytologic findings, such as large cell size, coarse nuclear chromatin, and frequent and prominent nucleoli. According to the findings that LCNEC and SCLC are closely related biologically and that their histopathologic distinction may be difficult and also that survival after surgical resection is almost equivalent, the need for the critical distinction between the 2 tumor categories should now be open to question. It is worth considering that a diagnosis of high-grade 
TABLE 4. The site of first documented recurrence $(n=35)$

\begin{tabular}{lc}
\hline Site & No. of cases $(\%)$ \\
\hline Distant metastases & $20(56)$ \\
Brain & 8 \\
Liver & 7 \\
Bone & 5 \\
Lung & 3 \\
Locoregional recurrence & $12(35)$ \\
Mediastinal node & 8 \\
Supraclavicular node & 4 \\
Bronchial stump & 3 \\
Both sites simultaneously & $3(9)$ \\
\hline
\end{tabular}

TABLE 5. Time to recurrence $(n=35)$

\begin{tabular}{lc}
\hline Time to recurrence & No. of cases $(\%)$ \\
\hline $1 \sim 6$ mo & $18(50)$ \\
$7 \sim 12$ mo & $11(32)$ \\
$13 \sim 24$ mo & $3(9)$ \\
$>24$ mo & $3(9)$ \\
\hline
\end{tabular}

neuroendocrine tumor of the lung, covering both tumor categories, would be biologically correct and would provide information necessary for making a clinical decision in many situations. In the light of the clinicopathologic features described here, it is also natural to claim that in a lung tumor classification LCNEC is better classified as a subtype of the neuroendocrine neoplasm family, which consists of typical carcinoid tumors, atypical carcinoid tumors, and SCLC and not as a subtype of LCC.

The optimal treatment of patients with LCNEC remains to be established. Because their poor prognosis is comparable with that of SCLC, it appears necessary to clarify that combined modality treatment or other novel therapeutic approaches would be effective.

In conclusion, LCNEC should be recognized as having a poor prognosis. The survival of patients with stage I LCNEC was significantly poorer than that of patients with the same stage of poorly differentiated NSCLC of other histologic types. Because of the extremely poor prognosis and aggressive nature of this tumor, novel therapeutic approaches need to be explored.

We thank Ms T. Shimizu for excellent technical assistance and to Mr S. Osaka for photographs.

\section{References}

1. Arrigoni MG, Woolner LB, Bernatz PE. Atypical carcinoid tumors of the lung. J Thorac Cardiovasc Surg. 1972;64:413-21.

2. Travis WD, Linnoila RI, Tsokos MG, Hitchcock CL, Cutler GB Jr, Nieman L, et al. Neuroendocrine tumors of the lung with proposed criteria for large-cell neuroendocrine carcinoma. An ultrastructural, immunohistochemical, and flow cytometric study of 35 cases. Am J Surg Pathol. 1991;15:529-53.
3. Colby TV, Koss MN, Travis WD. Large cell neuroendocrine carcinoma: In: Colby TV, Koss MN, Travis WD, editors. Tumors of the lower respiratory tract. Washington, DC: Armed Forces Institute of Pathology; 1995. p. 248-57.

4. Gould VE, Linnoila RI, Memoli VA, Warren WH. Neuroendocrine cells and neuroendocrine neoplasms of the lung. Pathol Annu. 1983; 18:287-330.

5. Warren WH, Faber LP, Gould VE. Neuroendocrine neoplasms of the lung: a clinicopathologic update. J Thorac Cardiovasc Surg. 1989;98: 321-32.

6. Warren WH, Gould VE, Faber LP, Kittle CF, Memoli VA. Neuroendocrine neoplasms of the bronchopulmonary tract: a classification of the spectrum of carcinoid to small cell carcinoma and intervening variants. J Thorac Cardiovasc Surg. 1985;89:819-25.

7. Warren WH, Memoli VA, Gould VE. Well differentiated and small cell neuroendocrine carcinomas of the lung: two related but distinct clinicopathologic entities. Virchows Arch. 1988;55:299-310.

8. Travis WD, Colby TV, Corrin B, Shimosato Y, Brambilla E. Histological typing of lung and pleural tumours. 3rd ed. Berlin: Springer; 1999.

9. Jiang SX, Kameya T, Shoji M, Dobashi Y, Shinada J, Yoshimura H. Large cell neuroendocrine carcinoma of the lung: a histologic and immunohistochemical study of 22 cases. Am J Surg Pathol. 1998;22: 526-38.

10. Gracia-Yuste M, Matilla JM, Alvarez-Gago T, Duque JL, Heras F, Cerezal LJ, et al. Prognostic factors in neuroendocrine lung tumors: a Spanish multicenter study. Ann Thorac Surg. 2000;70:258-63.

11. Garretta A, Ceresoli GL, Arrigoni G, Canneto B, Reni M, Cigala C, et al. Diagnostic and therapeutic management of neuroendocrine lung tumors: a clinical study of 44 cases. Lung Cancer. 2000;29:217-25.

12. Hernabek P, Hutter RVP, Sobin LH, Wager G, Wittekind Ch, editors. TNM atlas. 4th ed. Berlin: Springer; 1997.

13. Kaplan EM, Meier P. Nonparametric estimations from incomplete observations. J Am Stat Assoc. 1958:53:457-81.

14. Mooi WJ, Dewar A, Springall D, Polak JM, Addis BJ. Non-small cell lung carcinomas with neuroendocrine features: a light microscopic, immunohistochemical and ultrastructural study of 11 cases. Histopathology. 1988;13:329-37.

15. Travis WD, Rush W, Flieder DB, Falk R, Fleming MV, Gal AA, et al Survival analysis of 200 pulmonary neuroendocrine tumors with clarification of criteria for atypical carcinoid and its separation from typical carcinoid. Am J Surg Pathol. 1998;22:934-44.

16. Miyake Y, Kodama T, Yamaguchi K. Pro-gastrin-releasing peptide (31-98) is a specific tumor marker in patients with small cell lung carcinoma. Cancer Res. 1994;54:2136-40.

17. Yamaguchi K, Aoyagi K, Urakami K, Fukutani T, Maki N, Yamamoto $\mathrm{S}$, et al. Enzyme-linked immunosorbent assay of pro-gastrin-releasing peptide for small cell lung cancer patients in comparison with neuronspecific-enolase measurement. Jpn J Cancer Res. 1995;86:698-705.

18. Takada M, Kusunoki Y, Masuda N, Matui K, Yana T, Ushijima S, et al. Pro-gastrin-releasing peptide (31-98) as a tumor marker of smallcell lung cancer: comparative evaluation with neuron-specific-enolase. Br J Cancer. 1996;73:1227-32.

19. Goto K, Kodama T, Hojo F, Kubota K, Kakinuma R, Matsumoto T, et al. Clinicopathologic characteristics of patients with nonsmall cell lung carcinoma with elevated serum progastrin-releasing peptide levels. Cancer. 1998;82:1056-61.

20. Van Zandwijk N, Jassem E, Bonfrer JMG, Mool WJ, Van Tinteren H. Serum neuron-specific-enolase and lactate dehydrogenase as predictors of response to chemotherapy and survival in non-small cell lung cancer. Semin Oncol. 1992;19:37-43.

21. Andoh M, Gemma A, Takenaka K. Serum neuron specific enolase level as a prognostic factor in non-small cell lung cancer. Int Med. 1994;33:271-6.

22. Pujol JL, Boher JM, Grenier J, Quantin X. Cyfra 21-1, neuron specific enolase and prognosis of non-small cell lung cancer: prospective study in 621 patients. Lung Cancer. 2001;31:221-31.

23. Travis WD, Gal AA, Colby TV, Klimstra DS, Falk R, Koss MN. Reproducibility of neuroendocrine lung tumor classification. Hum Pathol. 1998;29:272-9. 